\title{
Migraciones internacionales chiapanecas (2000-2007). Diferenciación socioespacial de contextos de expulsión
}

\author{
International Migrations from Chiapas (2000-2007). \\ Socio-spatial Differentiation of the Ejection Contexts \\ Guillermo Castillo / saudadegris@yahoo.com \\ http://orcid.org/0000-0001-8188-9929 \\ Jorge González / jorgos@unam.mx \\ http://orcid.org/0000-0002-2199-8389 \\ María José Ibarrola / ibarrola@igg.unam.mx \\ http://orcid.org/0000-0003-4501-0408 \\ Universidad Nacional Autónoma de México, México
}

\begin{abstract}
Regarding migration changes between Mexico and the USA, this study focuses on the increase and diversification of migration between Chiapas and the USA during the period 2000-2007. This paper argues that not only economic conditions are the explanation to these migrations but also, in certain regions, political processes and impacts of natural disasters were important drivers for migration - a combination of causes in the context of migration-. Based on different sources (indicators of migration intensity, index on the remittance reception, migratory censuses, demographic surveys, quantitative and qualitative migratory studies), the increase in migration is shown at a state and regional level. Furthermore, the increase of migration in certain regions is assessed in relation with its causes (social, environmental, political and economical) showing that, migrations are multicausal processes spatially differentiated on the basis of the migrants' place of origin.
\end{abstract}

Key words: international migration, Chiapas, migration contexts, migrants, development.

Resumen: En el marco de las transformaciones de la migración México-Estados Unidos (EU) en el cambio de siglo, este artículo tiene como objetivo abordar el crecimiento y diversificación de las migraciones chiapanecas a EU (2000-2007). El aporte del trabajo es mostrar que si bien las condiciones económicas son relevantes para explicar las migraciones, también en ciertas regiones chiapanecas hubo procesos políticos y de impactos de desastres naturales para el surgimiento de estas migraciones - una articulación de causas en los contextos de expulsión-. Utilizando diversas fuentes (censos, índices de recepción de remesas, encuestas, estudios migratorios cualitativos y cuantitativos), se muestra el aumento de la migración a nivel estatal y regional. Posteriormente, se indaga cómo la migración se intensificó en ciertas regiones chiapanecas y cuáles fueron las causas -socioambientales, políticas y económicas-. Esto muestra que las migraciones son procesos espacialmente diferenciados y multicausales en relación con los lugares de origen.

Palabras clave: migración internacional, Chiapas, contextos de expulsión, migrantes, desarrollo. 


\section{Introducción}

Por siglos, las migraciones internacionales, en tanto dinámicas de movilidad y relocalización (Gregory et al., 2009), han estado relacionadas a procesos socioeconómicos y políticos del mundo contemporáneo. Las migraciones han estado vinculadas con la invasión colonial europea, la Revolución Industrial y al desarrollo y consolidación del mercado capitalista mundial, pero también al surgimiento de los Estados nacionales, la urbanización, la industrialización y los conflictos bélicos mundiales (Castles y Miller, 1998: 283). Sin embargo, en el contexto de la globalización -como dinámicas de circulación de bienes, información y capital- (Márquez y Delgado, 2012) y de las reformas estructurales neoliberales en países desarrollados y en vías de desarrollo (Castles, 2003 y 2008), los procesos migratorios internacionales de carácter laboral han aumentado desde las últimas décadas del siglo XX (Márquez y Delgado, 2012; Castillo, 2016; Sassen, 2006). ${ }^{1}$

Uno de los ejemplos más destacados fue el caso de la histórica migración mexicana -documentada e indocumentada- a EU, que no obstante ya era una de las más grandes del mundo, entre finales del siglo XX y principios del XXI (1994-2007) experimentó un crecimiento sostenido (Delgado et al., 2009; Aragonés y Salgado, 2015; Durand y Massey, 2009; Pew Hispanic Center, 2014a y 2014b). En el quinquenio de 2000 a 2005, México fue el primer exportador de migrantes del mundo -con un flujo anual promedio de medio millón de personas-, y el segundo receptor de remesas a nivel internacional (Márquez y Delgado, 2012).

En el contexto de la migración México-EU y específicamente en el marco de estudios sobre las migraciones chiapanecas al vecino país del norte (Jáuregui y Ávila, 2007; Villafuerte y García, 2014; Burke, 2004; Aquino, 2012a; Rus y Rus, 2008; Nájera y López, 2012; Castillo, 2017; López et al., 2009), el objetivo de este artículo es abordar el acelerado incremento y la expansión de la migración chiapaneca a EU -a nivel estatal y de las regiones de Chiapas- a inicios del presente siglo (2000-2007). Con esto se muestra la diversificación y expansión de estas migraciones y de los sitios donde se originó. Así, uno de los ejes es el tratamiento de las migraciones mediante el énfasis en la diversidad de causas que conformaron los contextos de expulsión de migrantes -en los lugares de origen-.

1 Mientras que en el año 2000 se registraron 172 millones de migrantes internacionales que eran el 2.8\% de la población mundial-, tres lustros después, para el 2015, la cifra subió a 243.7 millones -que representaba el 3.3\% de la población del planeta-(Conapo, 2015b y 2017). 
Las preguntas de investigación que vertebran este trabajo son las siguientes: 1) ¿Cómo cambiaron/crecieron las migraciones chiapanecas a EU en la década pasada, a nivel estatal y de las diversas regiones chiapanecas? 2) En el marco de relaciones heterogéneas y contextuales entre las migraciones y los procesos de desarrollo, ¿cuáles fueron las causas del rápido crecimiento de esta migración y cómo fueron los comportamientos migratorios diferenciados entre las diversas regiones chiapanecas de origen de los migrantes? Esta segunda interrogante alude a cómo las combinaciones de diversas causas económicas, socioambientales, de conflicto político, entre otras- estuvieron relacionadas a la incorporación selectiva y diferenciada de ciertas regiones chiapanecas -en tanto "nuevos" lugares de expulsión/origen de migrantes-a la migración internacional a EU.

Se argumenta que si bien hay procesos económicos determinantes para explicar las migraciones chiapanecas - caída de precios del café y el maíz, crisis del agro, encarecimiento de la vida, etc.-, también hubo regiones y municipios donde las dinámicas políticas - de conflicto-y los impactos de los desastres naturales jugaron un papel clave para que acontecieran estas migraciones. Lo anterior se aborda en el contexto de planteamientos que señalan que, en ocasiones, la migración no puede atribuirse a una sola motivación y/o condición (Castles y Miller, 1998: 27; Castles, 2003 y 2008; De Haas, 2010).

En este sentido y como indica De Haas (2010), la explicación de las causas de los procesos migratorios internacionales no darse solo desde un modelo conceptual determinista y rígido (De Haas, 2010: 240). No limitarse a un esquema monocausal mecánico permite ver cómo se dio una concatenación y determinación mutua entre las diversas causas de la migración en los lugares de origen. Lo anterior hace patente que, en determinadas situaciones, el origen de los procesos migratorios tiene un carácter espacialmente diferenciado y es multicausal -en relación con las condiciones de expulsión de migrantes en los lugares de procedencia-.

El periodo por abordar es del año 2000 al 2007, cuando se observó el mayor crecimiento de las migraciones chiapanecas a EU -en especial en términos de los flujos de migrantes y la recepción de remesas-. ${ }^{2}$ La justificación

2 En un periodo de poco más de doce años (1995-2007) y de acuerdo con datos del Consejo Nacional de Población (Conapo, 2014) y del Banco de México, el crecimiento de la recepción de remesas para el caso de Chiapas creció más de cuarenta veces. Hubo un proceso de incremento del número de migrantes chiapanecos con intención de cruzar a EU, sobre todo en el lapso de 2000-2007 (Segob, Conapo, INM, SRE, STPS y Colef, 2006 y 2013). Asimismo, aumentó del número de chiapanecos deportados para esos periodos (Villafuerte y García, 2014: 29). 
de esta delimitación histórico/temporal obedece a dos criterios. Por una parte y en lo que respecta al inicio del periodo, si bien ya desde fines de la década de 1980 se observaron algunos efectos de las reformas estructurales en el ámbito rural, es hasta mediados de la década de 1990 - con la firma y entrada en vigor del Tratado de Libre Comercio de América del Norte- cuando se mostraron con mayor contundencia los efectos del neoliberalismo en el campo, la desarticulación del aparato productivo en el agro chiapaneco y los efectos del neoliberalismo en la caída de los precios del café y el maíz. ${ }^{3}$

Por otro lado, en lo concerniente al fin del periodo por abordar, a raíz de la crisis de la economía estadounidense de 2008, hubo un notorio descenso de los flujos de migrantes mexicanos en general (Ley y Peña, 2016), y de chiapanecos en particular (Villafuerte y García, 2014). Asimismo, aconteció una clara reducción de la recepción de remesas -a nivel nacional y del estado de Chiapas-; con lo cual se inició otra etapa de la migración México-EU (Ley y Peña, 2016: 4-19). ${ }^{4}$ Particularmente y como efecto de dicha crisis, la disminución de la migración mexicana y chiapaneca no documentada a EU estuvo determinada sobre todo por la contracción de los diversos nichos laborales de la economía estadounidense -construcción, manufactura, servicios y agricultura- y, en consecuencia, por la carencia/escasez de trabajos en que se insertaban los chiapanecos en el país vecino.

Para el caso de Chiapas, los datos de la Encuesta sobre migración en la Frontera Norte de México (EMIF-Norte) (Segob, Conapo, INM, SRE, STPS y Colef, 2006 y 2013) corroboran lo señalado por otros estudios de El Colegio de la Frontera Norte (Colef) a nivel nacional (Ley y Peña, 2016: 4-19). De esta manera, investigaciones como la EMIF-Norte muestran que a partir de 2008 se registró un drástico y sostenido decrecimiento del número de chipanecos sin documentación migratoria que intentaban cruzar la frontera para llegar a EU.

3 Es hasta fines de la década de 1990 cuando se registra el acelerado crecimiento de la migración chiapaneca a EU.

4 Algunos de los rasgos de la nueva etapa de la migración mexicana a EU que inició a raíz de la crisis de la economía norteamericana del 2008 son: la disminución de la migración (especialmente la no documentada); el descenso de las deportaciones (derivado del menor número de migrantes que intentan cruzar la frontera); los tiempos de estancias en EU de los migrantes mexicanos deportados se han prolongado; se ha incrementado tanto la separación familiar derivada de las deportaciones, como el número de mujeres migrantes; se han diversificado los destinos de los mexicanos en EU; y el sector de servicios está concentrando la inserción laboral de los migrantes mexicanos (Ley y Peña, 2016: 4-19). 


\section{Estrategia metodológica, fuentes revisadas y datos utilizados}

Al considerar que los ejes de indagación del artículo son la migración chiapaneca a EU (2000-2007) y la diversidad de contextos y causas de expulsión de migrantes, en el desarrollo de la estrategia metodológica se recurrió a dos tipos de fuentes y datos: 1) a las investigaciones e información oficiales de carácter cuantitativo (Segob, Conapo, INM, SRE, STPS y Colef, 2006 y 2013) y 2) a estudios cualitativos de corte socioeconómico, demográfico y antropológico (Burke, 2004; Rus y Rus, 2008; Aquino, 2012a y 2012b; Cruz y Barrios, 2009; Castillo, 2015 y 2017; Villafuerte y García, 2008a, 2014; Villafuerte, 2015; López et al., 2009; Escobar et al., 2006). En lo concerniente al primer punto, también se toma en consideración información y datos del Instituto Nacional de Estadística y Geografía (INEGI) y del Programa de la Naciones Unidas para el Desarrollo (PNUD) para dar cuenta del contexto socioeconómico y demográfico de Chiapas a inicios del presente siglo -cuando se dio el acelerado aumento de las migraciones chiapanecas a EU-.

Respecto a los datos que permitan reconstruir la migración chiapaneca y su rápido crecimiento a principios de este siglo, se utilizaron los datos de la EMIF-Norte (Segob, Conapo, INM, SRE, STPS y Colef, 2006 y 2013) sobre migrantes chiapanecos que intentaban cruzar a EU -desde mediados de 1990 y hasta 2007-. ${ }^{5}$ Dentro del vasto conjunto de datos de la EMIFNorte, también se utilizó información sobre la migración chiapaneca a una escalar menor, a nivel de las regiones socioeconómicas que conforman esta entidad federativa del sureste mexicano. Esto permitió hacer un seguimiento socioespacial diferenciado sobre el incremento de la migración internacional chiapaneca, dependiendo de la región de origen, lo cual apuntó el eje hacia la

5 La EMIF-Norte es realizada desde mediados de la década de 1990 con el soporte y apoyo de varias dependencias oficiales del gobierno mexicano: Secretaría de Gobernación (Segob), Consejo Nacional de Población (Conapo), Instituto Nacional de Migración (INM), Secretaría de Relaciones Exteriores (SRE), Secretaría de Trabajo y Previsión Social (STPS) y El Colegio de la Frontera Norte (Colef). La EMIF-Norte provee información de diversa índole sobre procesos migratorios internos e internacionales a EU; desde los migrantes por entidad federativa de origen que se dirigen a la frontera y tienen la intención de cruzar al vecino país del norte, pasando por los migrantes que piensan permanecer únicamente en la frontera norte de México, hasta cifras de las deportaciones de mexicanos sin documentos migratorios por parte del gobierno estadounidense, así como datos de aquellos migrantes de retorno que vuelven de EU a México (Segob, Conapo, INM, SRE, STPS y Colef, 2006 y 2013). 
idea de diversos contextos de expulsión determinados por variadas causas, así como las disímiles tendencias de crecimiento migratorio entre las distintas regiones de Chiapas. ${ }^{6}$

Asimismo, se complementó esta información con el Índice de Intensidad Migratoria (IIM) a nivel municipal y estatal del Consejo Nacional de Población (Conapo, 2014) ${ }^{7}$ y con las relaciones históricas de recepción de remesas a nivel estatal para Chiapas (Banco de México, 2016) del periodo estudiado.

En lo que concierne a la diferenciación espacial de los procesos de salida de migrantes en distintos municipios, relacionado con los diversos contextos de expulsión, fueron de utilidad los datos de la EMIF-Norte (Segob, Conapo, INM, SRE, STPS y Colef, 2006 y 2013) sobre los migrantes y deportados por región de origen de Chiapas. También se recurrió a distintos estudios socioeconómicos y antropológicos sobre las causas de los procesos migratorios internacionales originados en diversas regiones de Chiapas, desde Los Altos (Burke, 2004; Rus y Rus, 2008) y La Meseta Comiteca Tojolabal (Aquino, 2012a y 2012b; Cruz y Barrios, 2009; Castillo, 2015 y 2017), hasta La Frailesca, La Sierra y El Soconusco (Villafuerte y García, 2008a, 2014; Villafuerte, 2015; López et al., 2009; Escobar et al., 2006).

\section{Andamiaje teórico, la migración como movilidad humana con causas estructurales}

Cabe precisar que en este artículo se concibe la migración internacional como diversas dinámicas de movilidad espacial de población humana (de

6 Chiapas, con 118 municipios, se divide en quince regiones: Metropolitana, Valles Zoque, Mezcalapa, De los Llanos, Altos Tzeltal Tzotzil, Frailesca, De los Bosques, Norte, Istmo Costa, Soconusco, Sierra Mariscal, Selva Lacandona, Maya, Tulijá Tzeltal Chol, Meseta Comiteca Tojolabal.

7 El IIM fue diseñado por el Conapo con el objetivo de distinguir las regiones y microrregiones del país donde los procesos migratorios tenían una mayor importancia (Conapo, 2010 y 2000: 9). Para ello se establecieron dos escalas de trabajo: una a nivel de cada entidad federativa, y otra para los diversos municipios de cada entidad federativa. El IIM se obtiene al establecer una relación entre el total de hogares, el porcentaje de hogares que reciben remesas, el porcentaje de los hogares con emigrantes en EU del quinquenio anterior, el porcentaje de los hogares con migrantes circulares el quinquenio anterior, y el porcentaje de los hogares con migrantes de retorno del quinquenio anterior (Conapo, 2000: 35 y 2010: 35). De esta manera, se tiene información social y espacialmente diferenciada de los procesos migratorios por municipio y entidad federativa. 
individuos y grupos) que, con miras a la satisfacción de las necesidades (económicas, sociales, políticas, etc.) y desplazándose a través de espacios y fronteras nacionales e internacionales, suponen procesos de relocalización y cambio de residencia (Gregory et al., 2009: 462). Los procesos migratorios acarrean cambios de diferente índole (socioeconómica, territorial, cultural y política) en los lugares de origen, tránsito y destino de los migrantes (Castillo, 2016 y 2017). Algunos autores (Massey, 2015; Duran y Massey, 2009) consideran que un adecuado tratamiento teórico de la migración supondría tener en cuenta varios ejes: a) las fuerzas que promueven la migración en los países de origen de los migrantes; b) los procesos de atracción que llevan a los migrantes a ciertos países; c) las motivaciones y anhelos de los migrantes; d) las redes y estructuras que unen los países de origen y destino, y que permiten que la migración ocurra.

Desde una perspectiva más amplia e integradora, el abordaje de las migraciones supone no solo la descripción de los espacios de tránsito y trayectorias, sino también las diversas causas y consecuencias de la misma (Gregory et al., 2009: 462). En el contexto de asimetrías económico-políticas y de una acentuada diferencia salarial entre países desarrollados y en vías de desarrollo (Bustamante, 1997), la migración internacional que se plantea contempla la consideración de los marcos estructurales de carácter socioeconómico en los países de origen y de destino (Márquez y Delgado, 2012; Delgado et al., 2009; Gregory et al., 2009); condiciones determinantes que impulsan a los migrantes a salir de sus lugares de procedencia en México/Chiapas y que los orientan/dirigen a ciertos mercados laborales necesitados de contingentes de mano de obra precarizada y flexible en diversos sitios de EU (Márquez y Delgado, 2012).

En este marco de ideas, cabe señalar que autores como De Haas (2010: 228) y Castles (2003 y 2008) han apuntado que, más allá de esquemas conceptuales lineales y deterministas, las relaciones e interacciones entre las migraciones y el desarrollo son problemáticas, complejas y heterogéneas. Particularmente para De Haas (2010), la migración tiene que concebirse como una dinámica de movilidad espacial poblacional, que es parte integral de un proceso de cambio más amplio relacionado con el desarrollo en los países de origen y destino. Pero la migración, una vez consolidada, también tiene sus propias lógicas internas de reproducción y cambio, y puede tener impactos sobre el desarrollo (De Haas, 2010: 228). De Haas (2010: 228) sostiene que la migración no puede entenderse como un proceso exógeno y ajeno a los contextos de origen, sino como un componente integral de los procesos de desarrollo de la vida social -de los contextos de origen de los migrantes-. 
Ahora bien, en este artículo se abordan, de manera crítica y con especial énfasis, las condiciones histórico-estructurales en el Estado nación de origen (y específicamente las de Chiapas y algunas de sus regiones) que propiciaron los procesos migratorios internacionales a EU a principios del siglo XXI. Condiciones que implican, entre otras, las adversas situaciones sociomateriales de vida y los precarios niveles de desarrollo socioeconómico en localidades rurales de distintas latitudes de esa entidad federativa.

Como argumento central de este trabajo, se sostiene que los diversos y diferenciados contextos de expulsión de los migrantes chiapanecos no siempre están relacionados con un solo factor/causa en específico. Los contextos de expulsión pueden relacionarse con múltiples causas - económicas, desastres naturales, conflictos internos, violencia política, entre otras- que están vinculadas y se determinan entre sí.

Es cierto que algunos procesos económicos relacionados con el cambio y deterioro del sector agropecuario jugaron un papel destacado para entender el rápido aumento de las migraciones chiapanecas a $\mathrm{EU}$ en gran parte de la década pasada (2000-2007). No obstante, también en ciertos municipios y regiones de esta entidad federativa las migraciones internacionales estuvieron vinculadas y determinadas tanto por contextos de conflicto sociales y los impactos de desastres naturales, como por las precarias condiciones materiales y económicas de vida.

\section{Estado de la cuestión: los estudios sobre migración internacional chiapaneca a EU}

Dentro del conjunto de trabajos desde las ciencias sociales en México que abordan la migración de chiapanecos a EU para el presente siglo, encontramos vertientes disciplinares y temáticas, desde la economía y la demografía (Jáuregui y Ávila, 2007; Villafuerte y García, 2006 y 2014; Nájera y López, 2012; López et al., 2009), hasta la antropología y la sociología (Burke, 2004; Cruz y Barrios, 2009; Aquino, 2012b; Rus y Rus, 2008; Angulo, 2008; Castillo, 2017).

Cabe señalar que los estudios de esta migración son relativamente recientes y tienen alrededor de tres lustros. Quizás esto esté relacionado a que los flujos de chiapanecos, que ya habían iniciado desde los últimos veinte años del siglo XX (Nájera y López, 2012: 465), fueron considerablemente abundantes y visibles para la academia hasta inicios de la década de 2000. Con base en la perspectiva disciplinar de análisis y en la escala desde la que se abordan los lugares de origen de la migración, pueden identificarse dos grupos en la bibliografía sobre la migración internacional chiapaneca. 
1) Por un lado, están aquellas investigaciones que, desde perspectivas disciplinares de carácter económico y sociodemográfico, trabajan a nivel de escala estatal en los lugares de origen -sin hacer una diferenciación entre las distintas regiones chiapanecas-, considerando la totalidad de esta entidad federativa en relación con las dimensiones demográficas, las causas económicas de los contextos de expulsión y los rasgos demográficos y socioeconómicos de la migración chiapaneca (Jáuregui y Ávila, 2007; Villafuerte y García, 2006, 2008a, 2008b y 2014; Villafuerte, 2015; Nájera y López, 2012; López et al., 2009).

2) Por otra parte, se ubica un variado conjunto de trabajos con abordajes antropológicos y sociológicos que, desde diversas reflexiones en torno a los cambios socioeconómicos y culturales de las comunidades campesinas e indígenas de origen, se enfocan en los procesos migratorios de carácter étnico y se abocan a indagar el surgimiento de estos flujos en determinadas regiones de Chiapas (Los Altos, La Frontera, El Soconusco, La Sierra, etc.) (Burke, 2004; Cruz y Barrios, 2009; Aquino, 2012a y 2012b; Rus y Rus, 2008; Angulo, 2008; Castillo, 2014 y 2015).

\section{Chiapas, del tránsito de la migración interna a la migración internacional}

Para el 2000 -año en que inicia un considerable aumento de la recepción de remesas-, Chiapas contaba con 3,911,529 habitantes (Conapo, 2015a: 1); tenía además al $54.3 \%$ del total de la población estatal viviendo en contextos rurales (en localidades de menos de 2,500 personas) (Conapo, 2015a: 5). En este tenor y para el mismo año, el sector que mayor población de 12 años y más estaba trabajando era el agropecuario con 47.9\%, después estaba el comercio y los servicios con $37.4 \%$, y luego la construcción y la industria con 12.4\% (Conapo, 2015a: 56). Chiapas tenía uno de los más altos registros de pobreza y pobreza extrema en el país; poseía los niveles de mortalidad materno-infantil más elevados y presentaba la menor esperanza de vida a nivel nacional (PNUD, 2010). La pobreza y la extrema pobreza se concentraban en el campo y se relacionaban con las crisis de las economías agrícolas vinculadas con la inestabilidad socioambiental de la producción y a la caída de los precios nacionales e internacionales del café y el maíz (Villafuerte y García, 2006: 104-107).

Este escenario de marginación histórico-estructural se expresaba en las precarias condiciones materiales de vida de gran parte de la población (PNUD, 2010; Conapo, 2015a). Situación que se reflejaba en los muy reducidos niveles de educación, salud e ingreso de Chiapas, los más bajos de 
México (PNUD, 2010: 41). Esto se vinculaba con dos dinámicas: 1) los procesos de exclusión de carácter socioétnico hacia los campesinos e indígenas; y 2) la acentuada e histórica inequidad de Chiapas, lo cual traía como consecuencia muy bajos niveles de desarrollo socioeconómico entre amplios grupos de la población (especialmente del campo) (Villafuerte, 2015; Castillo, 2014 y 2015). En este complejo y adverso escenario se da un acelerado crecimiento de migración chiapaneca no documentada a EU; el aumento en esta entidad fue mayor que el promedio nacional (Castillo, 2016).

Es conveniente recordar que la migración mexicana a EU se ha generado en el marco de contextos regionales con marcadas asimetrías políticoeconómicas y salariales entre estos dos países (Bustamante, 1997; Kearney, 1986; Verduzco, 2000; Santibáñez, 2000; Zúñiga et al., 2005; Delgado et al., 2009; Márquez y Delgado, 2012; Tuirán, 2000; Lozano et al., 2010; Ariza y Velasco, 2012; Castillo, 2016; Conapo, 2000 y 2010; Pew Hispanic Center, $2014 a$ y 2014b), entre los cuales hay una marcada desigualdad en los niveles de desarrollo (Delgado et al., 2009; Márquez y Delgado, 2012).

En gran parte del siglo pasado, las características que destacaban de esta migración no solo eran la masividad e historicidad de los flujos migratorios (Durand y Massey, 2009), sino también su eminente carácter masculino y no documentado (Durand, 2000 y 2007), de tipo económico laboral (Aragonés y Salgado, 2015), así como la fuerte concentración geográfica de los lugares de origen/expulsión de los migrantes mexicanos en un grupo de entidades del centro occidente del país (Durand, 2000); la denominada "región histórica de la migración”, de la que eran originarios cerca de la mitad de los migrantes mexicanos en EU y que estaba compuesta por los estados de Aguascalientes, Colima, Durango, Guanajuato, Jalisco, Michoacán, Nayarit, San Luis Potosí y Zacatecas (Durand y Massey, 2009).

Sin embargo, durante casi la totalidad del siglo XX y a semejanza de otras entidades del sur del país (como Campeche, Quintana Roo, Tabasco y Yucatán), la participación de Chiapas en la migración mexicana indocumentada a EU fue muy reducida (Durand y Massey, 2009; Villafuerte y García, 2006). Todavía para el año 2000, el IIM de Chiapas era de los más bajos, con un registro negativo de -1.27065 y en el penúltimo sitio del país (sólo delante de Tabasco) (Conapo, 2000: 35). Además, únicamente el 0.76\% de los hogares chiapanecos recibía remesas y solo $0.79 \%$ de los hogares contaba con migrantes en EU (Conapo, 2000: 35). En esta misma línea de hechos, en los registros de recepción de remesas del año de 1995, Chiapas tenía uno de los últimos lugares a nivel nacional (Conapo, 2000 y 2014; Banco de México, 2016). 
Desde un abordaje histórico-geográfico de la migración México-EU, algunos autores (Durand y Massey, 2009; Durand, 2000) han señalado que, durante el siglo XX, la migración internacional de carácter laboral no documentada no acontecía o estaba muy escasamente relacionada con entidades federativas de altos índices de marginación y con acentuadas condiciones de pobreza -como el caso de Chiapas-. Según estos estudiosos, dicha relación no vinculante entre migración y pobreza se debía a los altos costos económicos y sociales que implicaban las trayectorias migratorias transfronterizas al vecino país del norte (Durand y Massey, 2009: 78-87). De este modo, en gran parte de la pasada centuria, varios estados de la región sur de México (como Veracruz, Tabasco, Campeche, Yucatán, Quintana Roo y Chiapas) prácticamente no tuvieron migración internacional a EU (Durand y Massey, 2009: 78-87).

En cambio, Chiapas, para el siglo pasado, tuvo procesos migratorios de carácter interestatal entre diferentes regiones chiapanecas y flujos de carácter intra-estatal con otras entidades federativas del país (Villafuerte y García, 2014: 3-20). Respecto a las migraciones internas, la movilidad de población dentro de Chiapas estuvo presente durante buena parte del siglo XX y estaba determinada tanto por una estructura agraria altamente concentrada, como por el desarrollo de plantaciones que necesitaban mano de obra con conocimiento de las labores del campo (jornaleros agrícolas) (Villafuerte y García, 2014: 7). Mientras diversos municipios de los Altos de Chiapas densamente poblados y con fuertes necesidades de recursos productivos expulsaban parte de su población, los procesos de colonización de la Selva durante el siglo XX atrajeron un considerable volumen demográfico de personas de diferentes grupos socioculturales de varios lugares de esta entidad federativa del sureste mexicano (Villafuerte y García, 2014: 14-15).

Posteriormente, a partir de la década de 1970, surgieron y se consolidaron procesos migratorios de chiapanecos hacia entidades del sur y centro del país (Veracruz, Tabasco, Quintana Roo y Ciudad de México). Estas migraciones chiapanecas a otros estados estuvieron relacionadas con la inserción laboral temporal a determinadas actividades productivas de ciertos mercados laborales, como la industria de la construcción. Tales fueron los casos de campesinos chiapanecos que respondieron a la amplia demanda de trabajadores para el desarrollo del megaproyecto turístico de Cancún y de las explotaciones de yacimientos de gas y petróleo de Tabasco (Villafuerte y García, 2014: 16-17).

Ya para fines del siglo pasado, hubo registros de la migración no documentada de chiapanecos de origen rural a EU (Nájera y López, 2012: 465; 
Villafuerte y García, 2008b). Poco después, a partir de mediados de la década de 1990, la EMIF-Norte (Segob, Conapo, INM, SRE, STPS y Colef, 2006 y 2013) comenzó a dar cuenta de esta migración internacional chiapaneca, y, a su vez, el Banco de México (Banco de México, 2016) documentó el envío de remesas a Chiapas. Sin embargo, es hasta principios del siglo XXI cuando se observó un incremento notorio de esta migración internacional (Segob, Conapo, INM, SRE, STPS y Colef, 2006 y 2013; Conapo, 2014); con lo cual, en menos de un siglo y considerando la migración interna dentro de Chiapas como el origen de diversos procesos de reacomodo y relocalización de personas, se conformó un tercer sistema de movilidad de la población chiapaneca, con motivaciones principalmente económico-laborales, pero ahora de carácter internacional.

\section{Migraciones chiapanecas internacionales a principios de siglo XXI}

\section{Caracteristicas y crecimiento de la migración chiapaneca (2000-2007)}

Algunos autores han señalado que la migración internacional chiapaneca comenzó en la penúltima década del siglo XX (Nájera y López, 2012: 465). No obstante, dada la acotada dimensión del número de personas involucradas, todavía para la década de 1990, Chiapas no figuraba en ese tiempo como uno de los principales estados mexicanos expulsores de migrantes a EU (Durand y Massey: 2009). Por el contrario, dado su bajo IIM, aún para el 2000, esta entidad federativa ocupaba los últimos lugares a nivel nacional (Conapo, 2000: 35). Sin embargo, para los primeros años de la década pasada (2000-2007) y de acuerdo con la EMIF-Norte (Segob, Conapo, INM, SRE, STPS y Colef, 2006 y 2013) e informes de Conapo (2000, 2010 y 2014), esta migración chiapaneca de carácter laboral a EU creció de manera acelerada y tomó significativas proporciones (véanse Gráfico 1 y $2^{8}$ ).

En términos relativos y para el periodo abordado, Chiapas fue una de las nuevas entidades federativas que destacó por sus notorios procesos de expulsión de migrantes a EU (Villafuerte y García, 2014; Castillo, 2016; Segob, Conapo, INM, SRE, STPS y Colef, 2006 y 2013), así como por el acelerado crecimiento de recepción remesas (véase Gráfico 2). Este periodo de crecimiento de la migración internacional chiapaneca tuvo su fin en 2008, con la crisis de la economía norteamericana y la consecuente contracción de empleos para los migrantes.

8 Todos los gráficos y la Tabla 1 se encuentran en el Anexo, al final del presente artículo (Nota del editor). 
Se trató de una migración de carácter económico-laboral, principalmente no documentada; y en su mayoría, los migrantes eran jóvenes hombres en edades de entre 20 y 40 años con bajos niveles de escolaridad -aunque también había mujeres migrantes- (Nájera y López, 2012: 485; Segob, Conapo, INM, SRE, STPS y Colef, 2006 y 2013). Los lugares de origen de la migración chiapaneca a EU se encontraban fuertemente distribuidos en ciertas zonas rurales: el Soconusco, Los Altos de Chiapas y el Centro de Chiapas (Nájera y López, 2012: 489). En contraste, Tuxtla Gutiérrez y la región Metropolitana, en su conjunto, eran una de las que menores IIM tenían a nivel municipal en Chiapas (Conapo, 2000 y 2010).

Respecto a los procesos de inserción sociolaboral de los migrantes, durante buena parte de la primera década del siglo XXI algunos de los principales destinos de los chiapanecos en EU fueron Los Ángeles, California, Atlanta, Georgia y Raleigh, Carolina del Norte, entre otros, aunque también estaban las ciudades de Washington, Filadelfia y Nueva York (Villafuerte y García, 2008 a: 53). En cuanto a las dinámicas de incorporación laboral en el vecino país, los principales sectores en los que se ubicaron los chiapanecos fueron el agropecuario, la construcción y los servicios (López et al., 2009: 47).

Como se mencionó, el crecimiento de esta migración internacional fue muy acentuado a principios del siglo XXI (2000-2007). De acuerdo con datos de la EMIF-Norte (Segob, Conapo, INM, SRE, STPS y Colef, 2006 y 2013), en aproximadamente siete años el número de migrantes originario de Chiapas que intentaron cruzar la frontera México-EU se multiplicó por más de 30 veces, pasando de 3,446 chiapanecos en el año 2000 a 105,419 para el año 2007.

Estas migraciones chiapanecas no documentadas a EU, si bien presentaron un crecimiento acelerado entre 2000 y 2007, no fueron de carácter uniforme ni homogéneo; de hecho, en determinados años el aumento fue mucho más acentuado (véase Gráfico 1). Mientras que para el año 2000, la EMIF-Norte (Segob, Conapo, INM, SRE, STPS y Colef, 2006 y 2013) registró 3,446 chiapanecos con intención de cruzar la frontera hacia el vecino país; en el año 2002 hubo un sustantivo incremento y se registraron 36,307 migrantes; en el 2003 hubo otro cambio ascendente a 53,827 y escenarios similares se repitieron en el 2005 con 60,427 migrantes y en el 2006 con 118,50 chiapanecos (véase Tabla 1). Otros dos procesos relacionados con la movilidad de población que muestran el crecimiento de esta migración internacional entre 2000 y 2007 son el aumento de las dinámicas de retorno voluntario y las deportaciones de chiapanecos, así como el incremento de 
los traslados de migrantes muertos encontrados en la frontera México-EU y originarios de Chiapas (López et al., 2009: 50).?

Cabe mencionar que, como se verá en detalle en la siguiente sección, el crecimiento de los procesos migratorios internacionales a EU no fue igual ni homogéneo en todas las regiones de Chiapas. Por el contrario, se presentaron procesos diferenciados de incremento migratorio a lo largo del periodo de estudio, en donde, no obstante que en casi todas las regiones hubo un aumento de los flujos migratorios a EU, especialmente cuatro regiones (Altos Tzeltal Tzotzil, Soconusco, Meseta Comiteca Tojolabal y Sierra Mariscal) concentraron aproximadamente la mitad de todos los migrantes chiapanecos que intentaron cruzar la frontera (véase Tabla 1).

Respecto a la recepción de remesas económicas en Chiapas, se observó una tendencia de crecimiento muy semejante, pasando de 20 millones de dólares en 1995 a 921 en el año 2007, con lo cual para un periodo de doce años (1995-2007) el monto de dinero, vía remesas, se multiplicó más de cuarenta veces (véase Gráfico 2). En el orden de captación de remesas por entidad federativa, Chiapas pasó de tener el puesto 27 en el año 1995 a ocupar el sitio 11 para el 2007. El aumento de recepción de remesas en Chiapas fue uno de los más acentuados en todo el país, y mucho más marcado que el promedio nacional ${ }^{10}$ y que las tendencias de crecimiento mostradas por estados con larga tradición migratoria como Zacatecas, Michoacán y Guanajuato (Conapo, 2014). En cambio, otros estados del sureste del país con recientes migración a EU - como Yucatán, Campeche, Tabasco y Quintana Roo- mostraron, aunque en menor medida, procesos de incrementos de recepción de remesas similares a los de Chiapas (Conapo, 2014; Castillo, 2016).

No obstante, cabe precisar que el aumento de remesas en Chiapas no fue temporalmente homogéneo en este periodo. El incremento más drástico

9 Con base en datos de la Dirección General de Protección y Asuntos Consulares, estudiosos de la migración internacional chiapaneca documentan cómo, entre 2003 y 2005, hubo un incremento de los traslados de migrantes muertos de origen chiapaneco -al pasar de 79 en el año 2003 a 157 en el 2005- y de traslados de restos de personas chiapanecas en su intento por cruzar sin documentos migratorios la frontera -pasando de 13 en el año 2003 a 17 en el 2005- (López et al., 2009: 50).

10 A nivel del balance nacional de recepción de remesas, se pasó de 3,673 millones de dólares en el año 1995 a 26,059 para el año 2007; lo cual significó que el monto de 1995 se multiplicó por poco más de ocho veces para el 2007 (Conapo, 2014). No obstante el notorio incremento a nivel del conjunto nacional que esto representó, dicho porcentaje de crecimiento está muy por debajo del porcentaje de crecimiento de repción de remesas que mostró Chiapas, entidad que para el 2007 había multiplicado en más de 40 veces el monto de remesas recibidas en 1995 (Conapo, 2014; Castillo, 2016). 
y acelerado se dio en el cambio de siglo, en un lapso de ocho años, cuando se pasó de 20 millones en 1995 a 435 para el 2003 -en este periodo, el monto se incrementó en más de 20 veces- (Conapo, 2014; Banco de México, 2016). Posteriormente y en un lapso más breve (2003-2007), el aumento no fue tan sustantivo, pero aun así se mantuvo una tendencia de crecimiento, al pasar de 435 millones de dólares en el año 2003 a 921 para el año 2007, con lo cual la cifra de recepción de remesas apenas se duplicó (véase Gráfico 2).

\section{Contextos y causas de la migración internacional chiapaneca a EU}

En este tenor, y como han apuntado diversos autores que, desde perspectivas económicas y políticas, han abordado la relación entre migración internacional y desarrollo (Delgado et al., 2009; Márquez y Delgado, 2012; De Haas, 2010 y 2012), el origen/génesis de las migraciones internacionales - de carácter internacional no documentada y con motivaciones económicasremiten a dos grandes procesos socioeconómicos y políticos interrelacionados entre sí.

Por un lado, a la consideración de las causas histórico-estructurales en los contextos de vida del país de origen, que hacen salir a los migrantes de sus comunidades (en México) para satisfacer diversas necesidades: obtener empleos mejor remunerados, dinero para mejora de vivienda, obtención de recursos monetarios para acceder a servicios médicos, incrementar y mantener la infraestructura productiva, etcétera (Delgado et al., 2009; Márquez y Delgado, 2012; Castillo, 2016).

Por otra parte, a las fuerzas que atraen a estos migrantes -generalmente no documentados- a determinados lugares y trabajos en el país desarrollado de destino (Delgado et al., 2009), como ha sido la constante demanda de mano de obra barata, flexible y precarizada en ciertos nichos de la economía de EU (la agricultura, la construcción, la manufactura y los servicios) (Márquez y Delgado, 2012). No obstante, para el presente trabajo son de particular importancia las primeras, las que remiten a las adversas condiciones sociomateriales de vida -en los contextos de origen-, que obligan a los migrantes a salir de sus comunidades, con el propósito de conseguir recursos económicos en otros sitios/países y resolver sus diversas necesidades.

Para el caso de Chiapas, la relación entre la migración internacional y -la falta de- desarrollo en los contextos de origen ha sido abordada desde varias perspectivas disciplinares de las ciencias sociales y las humanidades. Así, diversos autores, desde ópticas económicas y sociodemográficas, han señalado que la migración internacional chiapaneca está asociada con la pobreza y la 
marginación estructural de esta entidad federativa, a la profunda crisis que padece la economía chiapaneca -especialmente en el sector agropecuariodesde la década de 1980 y a los drásticos efectos de las reformas estructurales y la desarticulación de los apoyos a la productividad y comercialización agrícola de pequeños y medianos productores en el agro mexicano en las últimas décadas (Villafuerte y García, 2008: 42; López et al., 2009: 51; Jáuregui y Ávila, 2007).

Diversos trabajos han dado cuenta de que la pobreza, en su vertiente estructural de carácter histórico -como las recientes dinámicas de pauperización derivadas de los impactos de las políticas neoliberales y la entrada en vigor del Tratado de Libre Comercio de América del Norte (TLCAN)-, fue uno de los marcos explicativos fundamentales para entender la migración internacional chiapaneca (Villafuerte y García, 2008a: 42). La economía estatal de Chiapas contaba con un importante sector agropecuario, caracterizado por un considerable subsector agrícola con procesos productivos de matiz más preponderantemente campesino que mercantil y con reducidos niveles de productividad en generalizados contextos de pauperización.

En este contexto, los cambios en el agro mexicano relacionados con las políticas de cambio estructural neoliberal y el oscilante comportamiento de los mercados internacionales de venta de productos agrícolas de las últimas décadas, han tenido un impacto muy negativo en los principales productos del campo chiapaneco -en específico de la producción del café y el maíz(López et al., 2009: 51) y en la desvalorización del trabajo agrícola chiapaneco (Nájera y López, 2012: 465-472).${ }^{11}$ Frente a este precario escenario en las localidades rurales, durante buena parte de la primera década del siglo XXI (2000-2007), una de las estrategias más recurrentes de los chiapanecos para sortear estos adversos contextos y satisfacer sus diversas necesidades socioeconómicas y de acceso a servicios sociales básicos - como atención médicafue la migración internacional a EU (Villafuerte y García, 2008a: 42) y el consecuente envío de remesas.

Es cierto que dentro de los estudios de la migración internacional chiapaneca hay quienes han enfatizado la importancia y centralidad de las causas económicas para comprender la salida de los chiapanecos hacia EU, en

11 Algunos autores han señalado que la economía chiapaneca lleva más de treinta años de pérdidas (Nájera y López, 2012: 271; López et al., 2009). En este contexto, centenas de miles de chiapanecos han experimentado una reducción de sus ingresos monetarios. Este escenario se relacionó con dos procesos socioeconómicos, Por un lado, el decrecimiento del valor del trabajo y la producción agrícola (de cultivos como el maíz y el frijol). Por otra parte, la disminución del salario real (Nájera y López, 2012: 472). 
referencia a las dinámicas relacionadas con el deterioro y desvaloración de los procesos productivos de corte agrícola y a la venta de cultivos como café y maíz (Villafuerte y García, 2008b; Jáuregui y Ávila, 2007). No obstante, otros estudios han señalado el papel de los impactos de los desastres naturales en localidades campesinas (de las regiones Soconusco y Sierra) (Villafuerte y García, 2014) y los efectos de conflictos políticos y la violencia oficial, a raíz del levantamiento armado en Chiapas, como factores para entender esta migración internacional (Cruz y Barrios, 2009; Aquino, 2012a; Castillo, 2017).

\section{Diversidad de procesos migratorios y heterogeneidad de contextos de origen}

Como se mostró previamente, en el marco de inicios de siglo (2000-2007), la migración internacional de chiapanecos a EU presentó un crecimiento acelerado pero desigual y no homogéneo en términos del número de migrantes chiapanecos anual -hubo ciertos años con acentuados aumentos- (véase Gráfico 1). En el contexto histórico del periodo de estudio y de acuerdo con datos de la EMIF-Norte (Segob, Conapo, INM, SRE, STPS y Colef, 2006 y 2013), se presentó una tendencia similar en términos de procesos de diferenciación socioespaciales de los lugares/contextos de origen al interior de Chiapas

No obstante que hubo un incremento de la migración a EU en todo Chiapas, las 15 regiones de dicha entidad no mostraron una tendencia homogénea y similar en relación con el número de migrantes que cada una de ellas expulsaba (véase Gráfico 3). Por el contrario, mientras ciertas regiones tuvieron un claro incremento en el número de migrantes chiapanecos que se dirigían a EU -y juntas concentraban aproximadamente la mitad de todos los migrantes a EU de Chiapas-, otras regiones no tenían procesos tan acelerados de incremento en el número de migrantes; también hubo aquellas que se ubicaron en medio de estos dos extremos (véase Tabla 1).

Para el periodo 2000-2007, y según información de la EMIF-Norte, las cuatro regiones chiapanecas que menor número de migrantes expulsaron a EU fueron la Maya, la Tulijá Tzeltal Chol, De los Llanos y la Frailesca ${ }^{12}$

12 La región Maya, ubicada en el extremo noreste de Chiapas, se compone de los siguientes cinco municipios: Catazajá, La Libertad, Palenque, Benemérito de las Américas y Marqués de Comillas. La región Tulijá Tzeltal Chol se localiza también en el noroeste en contigüidad geográfica con la región Maya y está conformada por siete municipios: Salto del Agua, Sitalá, Tumbalá, Chilón, Sabanilla, Tila y Yajalón. La región De los Llanos ubicada en el centro de Chiapas está constituida por siete municipios: Nicolás Ruíz, Acala, Totolapa, Venustiano Carranza, San Lucas, Chiapilla y Socoltenango. La región Frailesca, 
(véase Tabla 1). Para el año 2000, estas cuatro regiones en conjunto enviaron 270 migrantes del total de los 3,446 chiapanecos que intentaron cruzar la frontera con destino a EU, lo cual representó aproximadamente el 7.8\% de todos los migrantes chiapanecos. Para el 2004, del total de los 33,786 migrantes chiapanecos, estas cuatro regiones en conjunto tuvieron 2,786 migrantes, lo cual representó $8.2 \%$ de todos los chiapanecos con intenciones de cruzar la frontera. Finalmente, en el 2007, esta tendencia no había cambiado mucho y mostraba apenas un pequeño incremento: las cuatro regiones en su conjunto tenían sólo el $8.6 \%$ del total de los migrantes; juntas aportaban 9,074 de los 105,480 chiapanecos que intentaron cruzar la frontera ese año (véanse Gráfico 3 y Tabla 1).

En el extremo opuesto, para el mismo periodo (2000-2007), las cuatro regiones que concentraron un muy importante número de chiapanecos que intentaron cruzar la frontera para llegar a EU fueron: Altos Tzotzil Tzeltal, Meseta Comiteca Tojolabal, Sierra Mariscal y Soconusco ${ }^{13}$ (véanse Gráfico 3 y Tabla 1). Este grupo de cuatro regiones tiene varias características socioétnicas, económicas y geográficas, algunas de las cuales se relacionan con los procesos migratorios internacionales a EU. ${ }^{14}$

con colindancia con la región De los Llanos y ubicada en el centro este de Chiapas, está compuesta por cinco municipios: La Concordia, Villaflores, Montecristo de Guerrero, Ángel Albino Corzo y Villa Corzo. De los 112 municipios de Chiapas, el conjunto de estas cuatro regiones abarca 24 municipios, distribuidos en dos grandes zonas, en el noroeste y en centro-oeste.

13 La región Altos Tzotzil Tzeltal se ubica en el centro del estado, tiene colindancia en el sur con la región Meseta Comita Tojolabal y está conformada por 17 municipios: Amatenango del Valle, Chalchihuitán, Larráinzar, Mitontic, Oxchuc, Aldama, Santiago El Pinar, Chanal, Chenalhó, Huixtán, Pantelhó, San Cristóbal de las Casas, Tenejapa, Teopisca, Zinacantán, San Juan Cancucy Chamula. La región Meseta Comiteca Tojolabal, localizada al sur del estado y con frontera con Guatemala al sur y con la región Altos Tzotzil Tzeltal en el norte, está compuesta por siete municipios: Las Rosas, Maravilla Tenejapa, Las Margaritas, La Trinitaria, Tzimol, Comitán de Domínguez, La Independencia. La región Sierra Mariscal está integrada por diez municipios: Frontera Comalapa, La Grandeza, Motozintla, El Porvenir, Amatenango de la Frontera, Bella Vista, Bejucal de Ocampo, Chicomuselo, Mazapa de Madero y Siltepec. Finalmente, la región del Soconusco se compone de 17 municipios: Frontera Hidalgo, Cacahoatán, Metapa, Suchiate, Tapachula, Tuxtla Chico, Unión Juárez, Acacoyagua, Acapetahua, Escuintla, Huehuetán, Huixtla, Mazatán, Villa Comaltitlán y Tuzantán. Estas cuatro regiones tenían 49 de los 118 municipios de Chiapas.

14 Este conjunto abarca una zona significativa de Chiapas -principalmente en el extremo suroriental y parte del centro-; tiene una importante población indígena -concentrada 
No obstante tener una superficie mucho más reducida que la mitad del estado y menos de la mitad de la población chiapaneca, este grupo de cuatro regiones aportó aproximadamente poco más de la mitad de todos los migrantes que se dirigían a EU. De acuerdo con datos de la EMIF-Norte (Segob, Conapo, INM, SRE, STPS y Colef, 2006 y 2013), en el año 2000 estas cuatro regiones tuvieron 2,072 del total de los 3,446 migrantes chiapanecos, lo cual representó un aporte de poco más del 60.1\%. Para el 2004 se mantuvo una tendencia similar con una ligera baja, donde estas regiones enviaron 17,377 migrantes, que fue un poco más del $51.4 \%$ del total de 33,786 chiapanecos que se dirigieron a EU (véase Tabla 1). Finalmente, para el año 2007 hubo un repunte, y este cuarteto de regiones aportó casi el $61.7 \%$ de los migrantes, con 65,145 chiapanecos del total estatal de 105,480 (véase Tabla 1).

En particular, ciertos municipios de las regiones Altos Tzotzil Tzeltal y la Meseta Comiteca Tojolabal - con el caso de Las Margaritas- presentaron importantes y masivos procesos de desplazamiento interno relacionados con la guerra de baja intensidad en el contexto del levantamiento armado de 1994 (Cruz y Barrios, 2009). En el caso específico de Las Margaritas, estudios antropológicos y sociológicos han dado cuenta de cómo los desplazados internos - debido a la incursión del Ejército y la política de contención y control del gobierno mexicano frente al levantamiento armado de 1994- jugaron un papel muy importante para el surgimiento, crecimiento y rápida consolidación de la migración a EU de campesinos de ascendencia tojolabal de la parte central de Las Margaritas (Cruz y Barrios, 2009; Aquino, 2012b; Castillo, 2017).

Para el periodo abordado (2000-2007), Las Margaritas fue uno de los municipios chiapanecos que mayor crecimiento tuvo de la migración internacional a EU (Conapo, 2010; Segob, Conapo, INM, SRE, STPS y Colef, 2006 y 2013); asimismo, fue uno de los dos municipios dentro de la región Meseta Comiteca Tojolabal que más migrantes expulsó y que mostró uno de los crecimientos migratorios más acelerados para el periodo 2000-2007 (Segob, Conapo, INM, SRE, STPS y Colef, 2006 y 2013).

Aunado a esto y desde una dimensión de mayor magnitud relacionada con los impactos de los desastres naturales, la infraestructura productiva y de las viviendas de muchas localidades rurales de varios municipios de las regiones Sierra Mariscal y especialmente el Soconusco fueron estructuralmente afectadas por los huracanes Mitch en 1998 y Stan en 2005 (López et

en Los Altos de Chiapas con grupos tzotziles y tzeltales, y en Las Margaritas con los tojolabales-; además, muestra bajos niveles de desarrollo sociomaterial, y sus actividades productivas son de carácter agropecuario, sobre todo agrícolas. 
al., 2009: Villafuerte y García, 2014). Algunos estudios señalan que cerca del $40 \%$ de las localidades rurales del Soconusco perdieron casi por completo sus pertenencias, y en las zonas urbanas el impacto no fue de menor intensidad (Escobar et al., 2006). Las repercusiones de estos eventos naturales fueron un claro detonante y catalizador de la migración internacional a EU. Esto se relacionó directamente con el hecho de que en siete de los ochos años del periodo abordado (2000-2007) y dentro del grupo de estas cuatro regiones con mayor expulsión de chiapanecos, la del Soconusco fue la que claramente más migrantes expulsó hacia el vecino país (Segob, Conapo, INM, SRE, STPS y Colef, 2006 y 2013). ${ }^{15}$

\section{Conclusiones, pensando crítica y contextualmente la migración y el desarrollo}

Las migraciones internacionales, en tanto complejos y diversos procesos de movilidad humana a través de variadas fronteras, requieren para su abordaje de ejercicios de contextualización sociohistóricos y de la consideración de las heterogéneas situaciones de vida y desarrollo sociomaterial de las localidades de origen de los migrantes (De Haas, 2010 y 2012; Castillo, 2017). Lo anterior supone que, en el tratamiento del surgimiento y orígenes espaciales de las migraciones internacionales, es necesario considerar las condiciones estructurales y la compleja combinación de causas que estimulan y definen la migración en los países de procedencia de los migrantes (Márquez y Delgado, 2010; Massey, 2015; De Haas, 2010). Ahora bien, para el caso de las causas y orígenes de la migración internacional indagada en este trabajo se puede concluir lo siguiente:

1) El presente artículo analizó cómo el acentuado crecimiento de los procesos migratorios internacionales a $\mathrm{EU}$, originados en determinadas regiones chiapanecas a principios del siglo (2000-2007), no fue homogéneo y tuvo dinámicas de crecimiento irregulares/discontinuas y espacialmente diferenciadas (Segob, Conapo, INM, SRE, STPS y Colef, 2006 y 2013). Asimismo, los estudios e informes muestran que los flujos migratorios chiapanecos pueden tener diversas causas y disímiles contextos de origen (Villafuerte y García,

15 Salvo el año 2006 -cuando la región Altos Tzeltal Tzotzil tuvo un mayor registro-, en el resto de los años, la del Soconusco fue la región que más migrantes chiapanecos expulsó a EU (Segob, Conapo, INM, SRE, STPS y Colef, 2006 y 2013). En el año 2000 fueron 1,060; en 2001, 1,337; en 2002, 8,612; en 2003, 14,935; en 2004, 7,461; en 2005, 11,690; en 2006, 16,386; y para el 2007 tuvo un registro máximo de 23,159 (Segob, Conapo, INM, SRE, STPS y Colef, 2006 y 2013). 
2014; Cruz y Barrios, 2009; López et al., 2009; Castillo, 2017). En este tenor, el presente trabajo debate críticamente con aquellos abordajes que suponen que las migraciones son provocadas por una sola causa y de manera lineal y mecánica. Como señala De Haas (2010), las relaciones entre las migraciones concretas y los procesos de desarrollo son tan heterogéneas y complejas, que no pueden "encajar" en un modelo teórico determinista y rígido (De Haas, 2010: 240).

2) Es cierto que en el caso de algunas regiones de Chiapas - como la Metropolitana, Valles Zoque, Mezcalapa y los Llanos-, las causas económicas y las condiciones estructurales de falta de desarrollo sociomaterial fueron importantes en la explicación de procesos migratorios internacionales no documentados de carácter laboral (Nájera y López, 2012; Villafuerte y García, 2008a). No obstante, mediante el abordaje de lo acontecido en otras regiones específicas como el Soconusco, Sierra Mariscal y la Meseta Comiteca Tojolabal -las cuales tenían los mayores indicadores de crecimiento migratorio en Chiapas-, se demostró que no solo se trata de un determinismo económico de carácter rígido y absoluto. Por el contrario, en estas regiones los procesos relacionados con los impactos de desastres naturales (Villafuerte y García, 2014; López et al., 2009) y de conflicto social y desplazamiento interno (Cruz y Barrios, 2009; Castillo, 2017) también tuvieron un papel muy relevante en la comprensión de la migración chiapaneca no documentada a EU. En estas regiones en específico se presentó una heterogeneidad y articulación de diversas causas de la migración, presentándose una diferenciación socioespacial y de causas de los contextos de expulsión de los migrantes.

3) En este marco de ideas, el caso abordado sobre los procesos de diferenciación socioespaciales y demográficos en las migraciones internacionales originadas en las regiones chiapanecas muestra que, conforme a lo apuntado por autores como De Haas (2010 y 2012) y Castles (2003 y 2008), las relaciones e interacciones entre las migraciones internacionales y los procesos de desarrollo (en el país de origen) son heterogéneas, contextuales e históricas. Asimismo, para países en desarrollo - como el caso de México-, las diversas y específicas restricciones estructurales de los contextos locales en los procesos de desarrollo son condicionantes importantes para dar cuenta de las migraciones y sus causas (Castillo, 2016).

Dichas restricciones estructurales son variadas y heterogéneas, pueden abarcar desde la falta de empleos, bajos salarios, ausencia de acceso a diversos servicios (de educación, salud y vivienda digna) (Villafuerte y García, 2006), hasta los impactos socioambientales de diversos desastres naturales (huracanes, inundaciones, sequías) (Villafuerte y García, 2014) o contextos de conflicto interno y violencia (Cruz y Barrios, 2009). 
4) Finalmente, queda pendiente aún elaborar ejercicios de comparación entre lo ocurrido en el caso de Chiapas y otras entidades federativas de la región sureste (como Campeche, Yucatán, Tabasco y Quintana Roo); sobre todo, en la consideración de que estas otras entidades también tuvieron importantes y acelerados procesos de crecimiento de las migraciones durante buena parte de la década pasada (2000-2007).

\section{Referencias}

Angulo, Jorge Ignacio (2008), “De las Montañas de Chiapas al Soconusco, la Selva, Cancún, y ahora a Estados Unidos”, en Villafuerte, Daniel y García, María del Carmen [coords.], Migraciones en el sur de México y Centroamérica, México: Universidad de Ciencia y Artes de Chiapas y Porrúa.

Aquino, Alejandra (2012a), "De la milpa al field: la experiencia migratoria de jóvenes zapatistas en los campos de cultivo californianos", en Revista Liminar. Estudios Sociales y Humanisticos, vol. X, núm. 1, México: Centro de Estudios Superiores de México y Centroamérica, Universidad Autónoma de Chiapas.

Aquino, Alejandra (2012b), De las luchas indias al sueño americano, México: Centro de Investigación y Estudios Superiores en Antropología Social (CIESAS) y Universidad Autónoma Metropolitana-Xochimilco.

Aragonés, Ana María y Salgado, Uberto (2015), “Migración laboral México-Estados Unidos a veinte años del Tratado de Libre Comercio de América del Norte", en Revista Mexicana de Ciencias Política y Sociales, vol. LX, núm. 224, México: Universidad Nacional Autónoma de México.

Ariza, Marina y Velasco, Laura [coords.] (2012), Métodos cualitativos y su aplicación empírica. Por los caminos de la investigación sobre migración internacional, México: Instituto de Investigaciones Sociales, Universidad Nacional Autónoma de México y El Colegio de la Frontera Norte.

Banco de México (2016), "Ingresos por remesas, distribución por entidad federativa”, en Sistema de información económica, México. Disponible en: http://www.banxico.org. $\mathrm{mx} /$ SieInternet/consultarDirectorioInternetAction.do?accion=consultarCuadro\&id Cuadro $=$ CE100 [7 de septiembre de 2017].

Burke, Garance (2004), "Yucatecos y chiapanecos en San Francisco: la formación de comunidades de inmigrantes indígenas y su incorporación a un mercado laboral menguantes", en Fox, Jonathan y Rivera-Salgado, Gaspar [coords.], Indigenas mexicanos migrantes en los Estados Unidos, México: Cámara de Diputados, Universidad Autónoma de Zacatecas y Porrúa.

Bustamante, Jorge (1983), “The Mexicans are Coming: From Ideology to Labor Relations”, en International Migration Review, núm. 17, Estados Unidos: Center for Migration Studies.

Bustamante, Jorge (1997), Cruzar la linea. La migración de México a los Estados Unidos, México: Fondo de Cultura Económica.

Castillo, Guillermo (2014), "Migración transfronteriza en la era de la globalización y nuevos usos del territorio en las comunidades rurales de origen”, en La Investigación Social en México 2014, México: Universidad Autónoma del Estado de Hidalgo. 
Guillermo Castillo, Jorge González y María José Ibarrola. Migraciones internacionales chiapanecas (2000-2007). Diferenciación socioespacial de contextos de expulsión

Castillo, Guillermo (2015), "Migración y comunidad, cambios y reconfiguraciones socioterritoriales en localidades campesinas del sureste de Chiapas", en Revista Multidisciplina, núm. 22, México: Facultad de Estudios Superiores-Acatlán, Universidad Nacional Autónoma de México.

Castillo, Guillermo (2016), "Geografía de la migración mexicana a Estados Unidos", en Moncada, O. y López, A. [coords.], Geografía de México: una reflexión espacial contemporánea, México: Instituto de Geografía, Universidad Nacional Autónoma de México, Consejo Nacional de Ciencia y Tecnología, Instituto Nacional de Estadística y Geografía.

Castillo Guillermo (2017), "Migración internacional y cambio en los poblados de origen", en Revista Mexicana de Sociología, vol. 79, núm. 3, México: Universidad Nacional Autónoma de México.

Castles, Stephen y Miller, Mark (1998), The Age of Migration: International Population Movements in the Modern World, Estados Unidos: Palgrave y Macmillan and Guilford.

Castles, Stephen (2003), "Towards a Sociology of Forced Migration and Social Transformation”, en Sociology, vol. 37, núm. 1, Reino Unido: Sage.

Castles, Stephen (2008), "Understanding Global Migration: A Social Transformation Perspective", Conference on Theories of Migration and Social Change, Reino Unido: St Anne's College, Oxford University.

Conapo (2000), Indices de intensidad migratoria México-Estados Unidos, México: Consejo Nacional de Población.

Conapo (2010), Indices de intensidad migratoria México-Estados Unidos, México: Consejo

Nacional de Población.

Conapo (2014), Monto de remesas familiares anuales a México, 1990-2013, México: Consejo Nacional de Población.

Conapo (2015a), Principales Resultados de la Encuesta Intercensal 2015 Chiapas, México: Consejo Nacional de Población.

Conapo (2015b), Anuario de migración y remesas México 2016, México: Consejo Nacional de Población, Secretaría de Gobernación y Fundación BBVA.

Conapo (2017), Anuario de migración y remesas México 2017, México: Consejo Nacional de Población, Secretaría de Gobernación y Fundación BBVA.

Cruz, Dafne Isis y Barrios, Ana Elena (2009), Sur inicio de un camino. Una mirada global de los Derechos Humanos en la Frontera Sur de México, México: Asociación Latinoamericana de Organizaciones Promotoras del Desarrollo, Enlace Comunicación y Desarrollo.

De Haas, Hein (2010), "Migration and Development: A Theoretical Perspective", en International Migration Review, vol. 44, núm. 1, Estados Unidos: Center for Migration Studies.

De Haas, Hein (2012), “The Migration and Development Pendulum: A Critical View on Research and Policy”, en Internal Migration, vol. 50, núm. 3, Reino Unido: International Organization for Migration.

Delgado, Raúl et al. (2009), "Seis tesis para desmitificar el nexo entre migración y desarrollo", en Revista Migración y Desarrollo, vol. 12, México: Universidad Autónoma de Zacatecas. Durand, Jorge (2000), "Tres premisas para entender y explicar la migración México-Estados Unidos”, en Revista Relaciones, vol. 21, núm. 83, México: El Colegio de Michoacán.

Durand, Jorge (2007), "Nuevos escenarios geográficos de la migración mexicana a los Estados Unidos”, en Estrada, Margarita y Labazée, Pascal [coords.], Globalización y localidad: espacios, actores, movilidades e identidades, México: Publicaciones de la Casa 
Convergencia Revista de Ciencias Sociales, núm. 78, 2018, Universidad Autónoma del Estado de México

Chata, Centro de Investigaciones y Estudios Superiores en Antropología Social e Institut de Recherche pour le Développement.

Durand, Jorge y Massey, Douglas (2009), Clandestinos, Migración México-Estados Unidos en los albores del siglo XX, México: Universidad Autónoma de Zacatecas y Miguel Ángel Porrúa.

Escobar, Héctor et al. (2006), "Pobreza, desastres naturales y migración en las regiones Istmo-Costa, Sierra y Soconusco de Chiapas", en Observatorio de la Economía Latinoamericana, núm. 70, España: Servicios Académicos Intercontinentales.

Gregory, Derek et al. (2009), The Dictionary of Human Geography, Reino Unido: WileyBlackwell.

Jáuregui, Alfredo y Ávila, María (2007), “Estados Unidos, lugar de destino para los migrantes chiapanecos”, en Revista Migraciones Internacionales, vol. 4, núm. 1, México: El Colegio de la Frontera Norte.

Kearney, Michael (1986), "From the invisible hand to visible feet: Anthropological Studies of Migration and Development", en Annual Review of Anthropology, vol. 15, Estados Unidos: Annual Reviews, Stanford University.

Ley, Melissa y Peña, Jesús (2016), 20 Temas actuales y relevantes sobre la migración en México, México: El Colegio de la Frontera Norte.

López, Jorge et al. (2009), "Crisis económica y flujos migratorios internacionales en Chiapas”, en Revista Mexicana de Ciencias Politicas y Sociales, año 51, núm. 207, México: Universidad Nacional Autónoma de México.

Lozano, Fernando et al. (2010), "Contribución de las remesas a los ingresos públicos", en Revista Migración y Desarrollo, núm. 14, México: Universidad Autónoma de Zacatecas.

Márquez, Humberto y Delgado, Raúl (2012), Espejismos del Rio de Oro. Dialéctica de la migración y el desarrollo en México, México: Miguel Ángel Porrúa, Red Internacional de Migración y Desarrollo y Universidad Autónoma de Zacatecas.

Massey, Douglas (2015), “A Missing Element in Migration Theories”, en Migration Letters, vol. 12, núm. 3, Estados Unidos: Office of Population Research y University of Princeton.

Nájera, Jessica y López, Jorge (2012), “Migración de chiapanecos a los Estados Unidos, una visión desde la Encuesta sobre Migración en la Frontera Norte de México" (EMIFNorte)", en Berumen, Salvador y López-Arévalo, Jorge Alberto [coords.], Pobreza y migración: enfoques y evidencias a partir de estudios regionales en México, México: Centro de Estudios Migratorios y Secretaría de Gobernación.

Pew Hispanic Center (2014a), Estimates of Unauthorized Immigrants, for Largest Countries of Birth, Selected Years 1995-2012, Estados Unidos: Pew Hispanic Center.

Pew Hispanic Center (2014b), Unauthorized Immigrant Population Trends for States, Birth Countries and Regions, Estados Unidos: Pew Hispanic Center.

PNUD (2010), Informe Sobre Desarrollo Humano de los Pueblos Indígenas en México, México: Programa de las Naciones Unidas para el Desarrollo-Comisión Nacional Para el Desarrollo de los Pueblos Indios.

Rus, Diane y Rus, Jan (2008), "La migración de trabajadores indígenas de Los Altos de Chiapas en Estados Unidos, 2001-2005: el caso de San Juan Chamula”, en Villafuerte Daniel y García, María del Carmen [coords.], Migraciones en el sur de México y Centroamérica, México: Universidad de Ciencia y Artes de Chiapas y Miguel Ángel Porrúa.

Santibáñez, Jorge (2000), "Características recientes de la migración mexicana a Estados 
Guillermo Castillo, Jorge González y María José Ibarrola. Migraciones internacionales chiapanecas (2000-2007). Diferenciación socioespacial de contextos de expulsión

Unidos", en Turián, R. [coord.], Migración México-EU continuidad y cambio, México: Consejo Nacional de Población.

Sassen, Saskia (2006), "La formación de las migraciones internacionales: implicaciones políticas”, en Revista Internacional de Filosofía Politica, núm. 27, España: Universidad Autónoma de Madrid y Universidad Nacional de Educación a Distancia.

Segob, Conapo, INM, SRE, STPS y Colef (Secretaría de Gobernación, Consejo Nacional de Población, Instituto Nacional de Migración, Secretaría de Relaciones Exteriores, Secretaría del Trabajo y Previsión Social y El Colegio de la Fontera Norte) (2006), Encuesta sobre migración en la Frontera Norte de México, 2004, Serie anualizada 1995, 1999-2004, México: Segob, Conapo, INM, SRE, STPS y Colef.

Segob, Conapo, INM, SRE, STPS y Colef (2013), Encuesta sobre migración en la Frontera Norte de México, 2011, Serie anualizada 2004 a 2011, México: Segob, Conapo, INM, SRE, STPS y Colef.

Tuirán, Rodolfo (2000), Migración México-EU continuidad y cambio, México: Consejo Nacional de Población.

Verduzco, Gustavo (2000), "La migración mexicana a Estados Unidos. Estructuración de una selectividad histórica”, en Tuirán, Rodolfo [coord.], Migración México-EU continuidady cambio, México: Consejo Nacional de Población.

Villafuerte, Daniel y García, María del Carmen (2006), "Crisis rural y migraciones en Chiapas”, en Revista Migración y Desarrollo, vol. 1, núm. 6, México: Universidad Autónoma de Zacatecas.

Villafuerte, Daniel y García, María del Carmen (2008a), "Algunas causas de la migración internacional en Chiapas”, en Economia y Sociedad, vol. XIV, núm. 21, México: Universidad Michoacana de San Nicolás de Hidalgo.

Villafuerte, Daniel y García, María del Carmen (2008b), Migraciones en el sur de México y Centroamérica, México: Universidad de Ciencia y Artes de Chiapas y Miguel Ángel Porrúa.

Villafuerte, Daniel y García, María del Carmen (2014), “Tres ciclos migratorios en Chiapas: interno, regional e internacional”, en Revista Migración y Desarrollo, núm. 22, vol. 2, México: Universidad Autónoma de Zacatecas.

Villafuerte, Daniel (2015), “Crisis rural, pobreza y hambre”, en Liminar, Estudios Sociales y Humanisticos, vol. XIII, núm. 1, México: Centro de Estudios Superiores de México y Centroamérica, Universidad Autónoma de Chiapas.

Zúñiga, Elena et al. (2005), La migración México-Estados Unidos, México: Consejo Nacional de Población. 
Anexo

\section{Gráfico 1}

Emigrantes de Chiapas con destino a los Estados Unidos, 1995, 1999-2010.

Número de personas por año

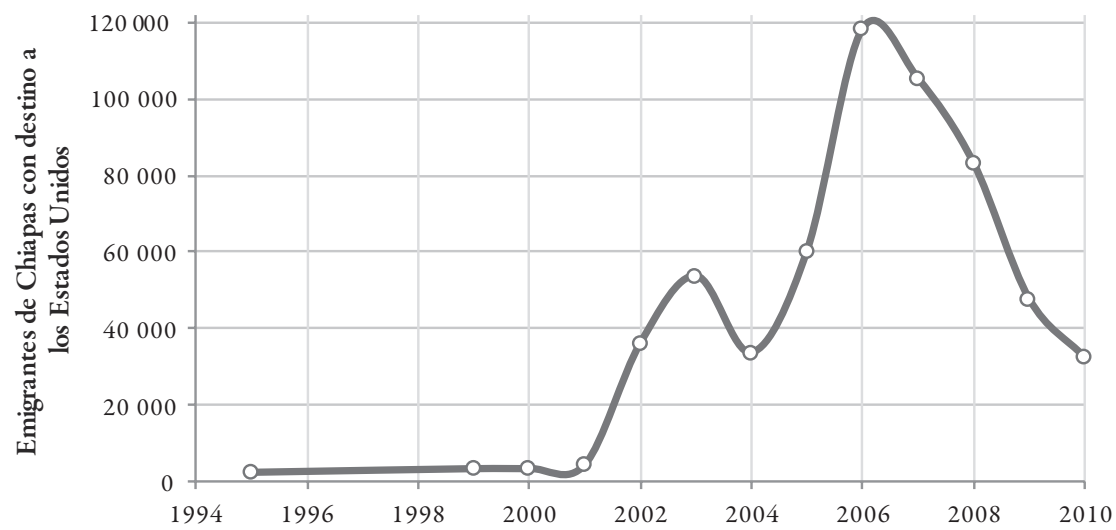

Fuente: Elaboración con base en la información de Segob, Conapo, INM, SRE, STPS y Colef (2006 y 2013).

\section{Gráfico 2}

Ingresos por remesas familiares en Chiapas, 1995, 2001-2010.

En millones de dólares por año

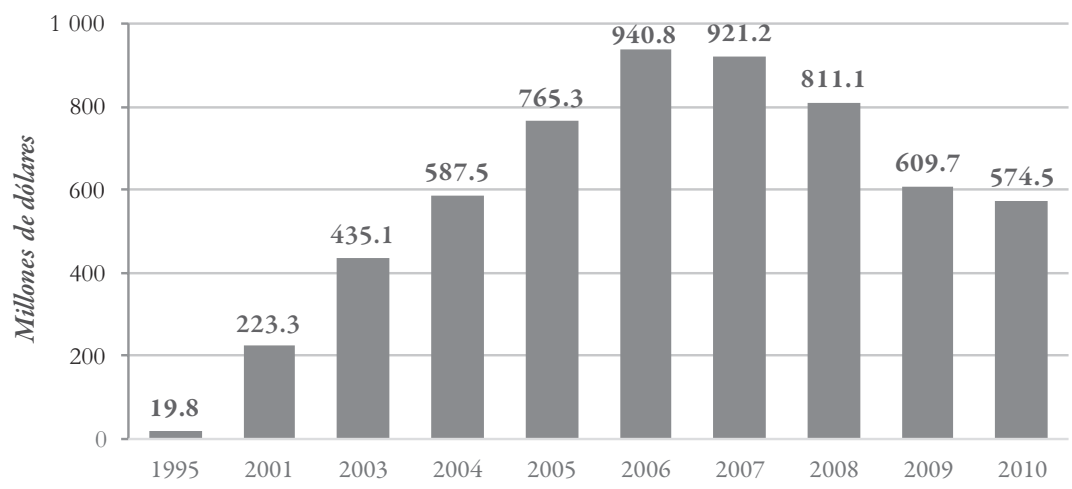

Fuente: Elaboración con base con base en la información de Conapo (2014) y Banco de México (2016). 


\section{Gráfico 3}

Emigrantes de Chiapas con destino a los Estados Unidos según la región socioeconómica de origen, 2000, 2004 y 2007. Número de migrantes por año

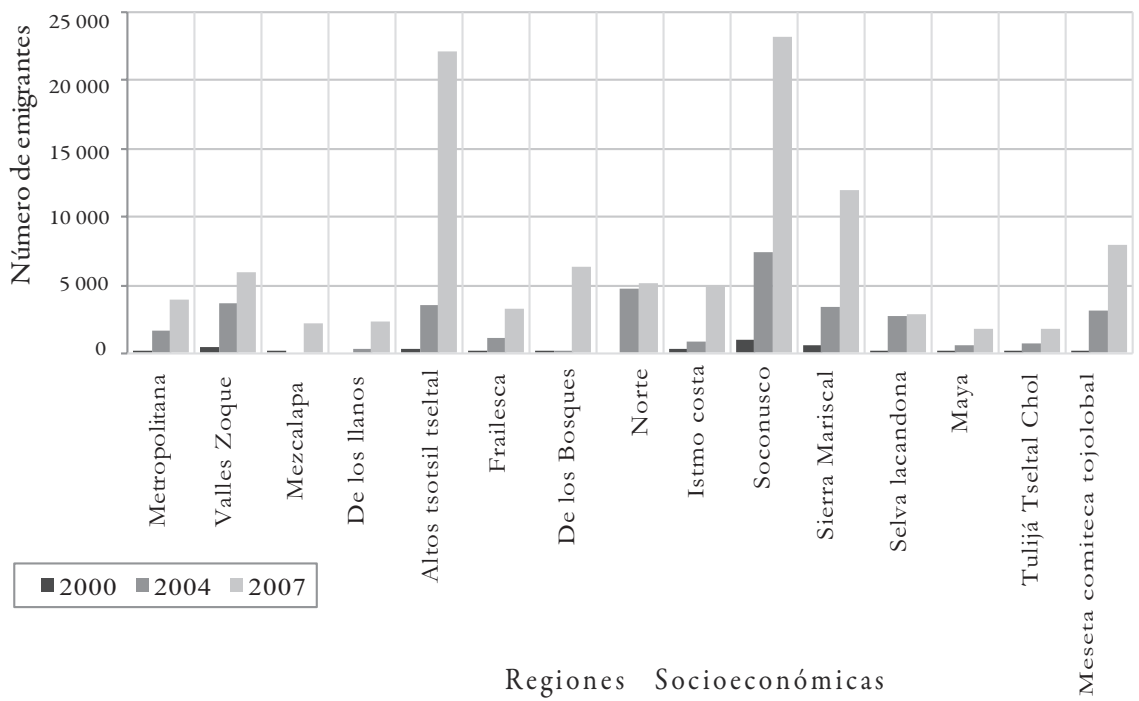

Fuente: Elaboración con base en la información de Segob, Conapo, INM, SRE, STPS y Colef (2006 y 2013). 


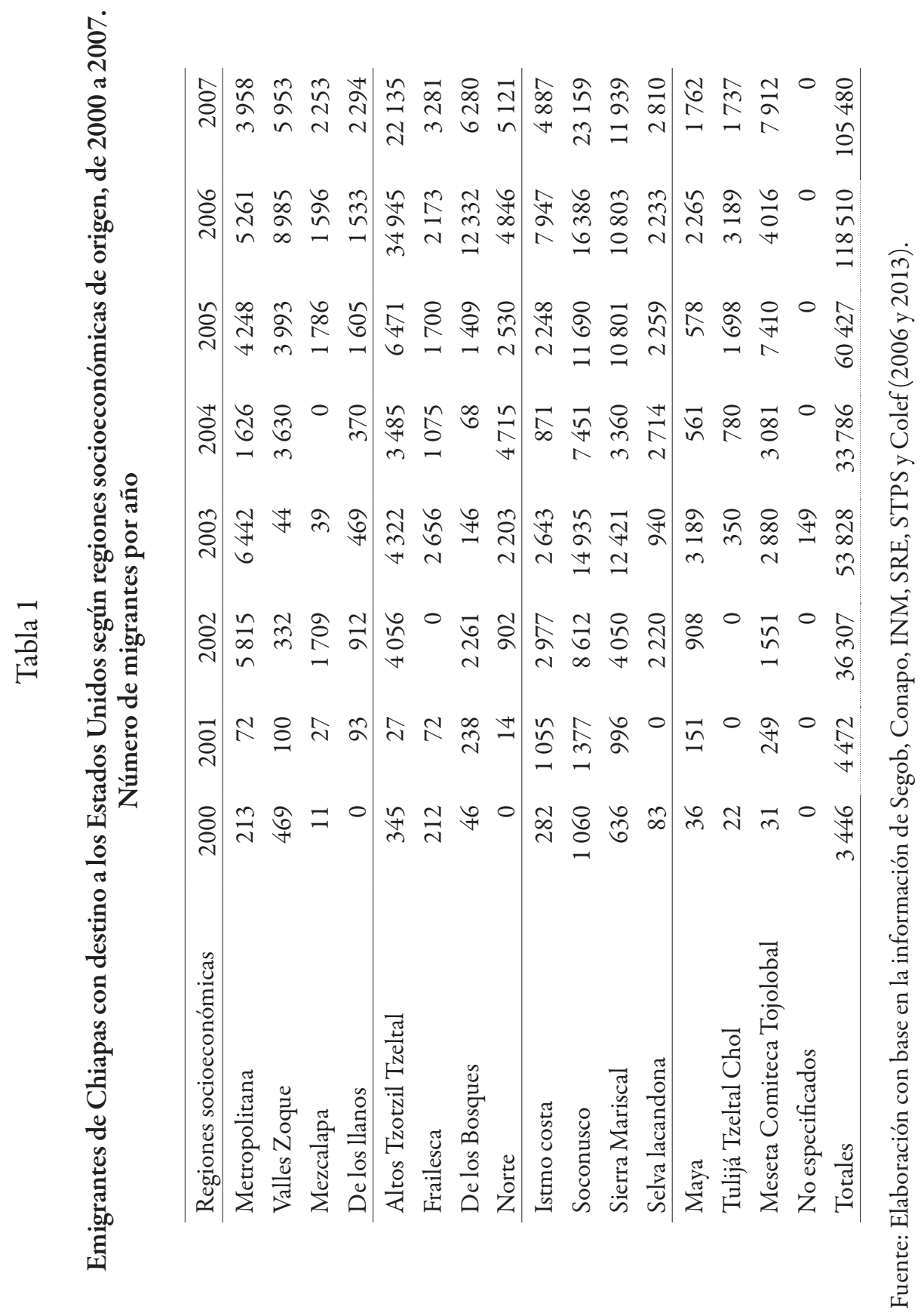


Guillermo Castillo Ramírez. Doctor en Antropología. Departamento de Geografía Social, Universidad Nacional Autónoma de México. Líneas de investigación: migración internacional, geografía de la migración, espacio. Publicaciones recientes: Castillo Ramírez, G., "Migración internacional y cambio en los poblados de origen”, en Revista Mexicana de Sociología, núm. 3, julio-septiembre, México: Instituto de Investigaciones Sociales, Universidad Nacional Autónoma de México (2017); Castillo Ramírez, Guillermo, "Geografía de la migración mexicana a Estados Unidos. Cambios y continuidades en las zonas expulsoras de migrantes", en Geografía de México: una reflexión espacial contemporánea, México: Instituto de GeografíaUniversidad Nacional Autónoma de México, Consejo Nacional de Ciencia y Tecnología, Instituto Nacional de Estadística y Geografía (2016); Castillo Ramírez, Guillermo, "Migración y comunidad, cambios y reconfiguraciones socioterritoriales", en Revista Multidisciplina, núm. 22, México: Universidad Nacional Autónoma de México (2015).

Jorge González. Maestro en Geografía. Departamento de Geografía Social, Universidad Nacional Autónoma de México. Principales líneas de investigación: migración internacional y migración interna. Publicaciones recientes: Ortíz-Âlvarez, María Inés, Tamayo-Pérez, Luz María, GonzálezSánchez, Jorge y Villaseñor-Franco, Alma, "Guanajuato, 'Ciudad Patrimonio de la Humanidad', ¿Oportunidad o desafío para el turismo sostenible?”, en $\mathrm{Ar}$ bor, vol. 193, núm. 785, España (2017). Doi: http://dx.doi.org/10.3989/ arbor.2017.785n3008; González-Sánchez, Jorge, "La evolución del paisaje cultural de la Alameda de la Ciudad de México. Del viejo paseo señorial a su decadencia y recuperación", en Zárate-Martín, Manuel Antonio [dir.], Paisajes culturales a través de casos de España y América, España: Universidad Nacional de Educación a Distancia (2016); Gutiérrez, María Teresa y Gonzáles, Jorge, "Principales retos de la distribución de población", en Geografía de México: una reflexión espacial contemporánea, México: Instituto de Geografía, Universidad Nacional Autónoma de México, Consejo Nacional de Ciencia y Tecnología-Instituto Nacional de Estadística y Geografía (2016).

María José Ibarrola. Doctora en Ciencias Ambientales. Departamento de Geografía Física, Universidad Nacional Autónoma de México. Principales líneas de investigación: agricultura, seguridad alimentaria y sustentabilidad. Publicaciones recientes: Ibarrola-Rivas, M. J. y Granados-Ramírez, R., "Diversity of Mexican diets and agricultural systems and their impact on the 
land requirements for food", en Land Use Policy, núm. 6, Australia (2017); Ibarrola-Rivas, M. J. y Nonhebel, S., "Variations in the Use of Resources for Food: Land, Nitrogen Fertilizer and Food Nexus", en Sustainability, vol. 8, núm. 12, Suiza (2016); Ibarrola-Rivas, M. J. y Nonhebel, S., "Assessing Changes in availability of land and water for food (1960-2050)", en Outlook on Agriculture, vol. 45, núm. 2, Estados Unidos (2016).

Recepción: 24 de noviembre de 2017.

Aprobación: 24 de mayo de 2018. 